\title{
Comparative strain analysis of 34CrMo4 steel and Inconel 738LC
}

\author{
M. Stamborská ${ }^{1 *}$, M. Losertová ${ }^{1}$, K. Konečná ${ }^{2}$, V. Mareš $\check{~}^{3}$, L. Horsák ${ }^{3}$ \\ ${ }^{1}$ Department of Non-ferrous Metals, Refining and Recycling, Faculty of Metallurgy and Materials Engineering, \\ VS̆B-Technical University of Ostrava, Czech Republic \\ ${ }^{2}$ Department of Material Engineering, Faculty of Metallurgy and Materials Engineering, \\ Vঙ̆B-Technical University of Ostrava, Czech Republic \\ ${ }^{3}$ Center of Advanced Innovation Technologies (CAIT), Vঙ̆B-Technical University of Ostrava, Czech Republic
}

Received 2 December 2014, received in revised form 14 January 2015, accepted 20 January 2015

\begin{abstract}
The comparative analysis of mechanical properties using a digital image correlation by Vic $2 \mathrm{D}$ software was performed for two types of high-strength materials. The strain analysis during tensile tests was carried out on the cylinder tensile specimens of $34 \mathrm{CrMo} 4$ steel and IN 738LC superalloy. Both materials showed similar strength but different ductility. While the $34 \mathrm{CrMo} 4$ steel showed typical necking of tensile specimens with ductile fracture surfaces, cracking of the IN 738LC became without necking, and the fracture morphology displayed mixed feature with ductile dimples or quasi-cleavage areas and cracked carbides. Microhardness measurements completed metallographic and fractographic studies of tensile samples.
\end{abstract}

K e y w or d s: 34CrMo4, IN 738LC, strain analysis, fracture surface

\section{Introduction}

The low-carbon $34 \mathrm{CrMo} 4$ steel with medium through-hardening is applied in machine parts of medium-duty or high toughness in the automotive and aerospace industry. Good performance of the $34 \mathrm{CrMo} 4$ steel at high pressures enables its application to gas cylinders. The steel is primarily produced as blanks - wire, universal mill plates, forgings, seamless tubes, hot-rolled billets, rolled bars, hot-rolled strips or steel for refining [1-4]. The heat-treatable steel could be in different thermal treated stages, as austenitized and quenched or austenitized, quenched and tempered. So, the microstructure could be formed of martensite or transformed martensite. Although no susceptibility to tempering brittleness is manifested, this steel possesses welding difficulties and a tendency to chilling cracking after hot forming, initiated mainly by indentations and surface defects [5-8].

The Inconel $738 \mathrm{LC}$ (IN 738LC) is a nickel-base low-carbon superalloy used for high-temperature applications, as gas turbine engines. The unique mechanical properties of the IN 738LC alloy at high temperatures are ensured by a Ni-base solid solution (fcc $\gamma$ matrix) that is hardened by suitable solutes, as $\mathrm{Al}$,
Ti, Nb, Ta, Cr, W, Co and Mo, hereinafter by fine $\gamma$ ' precipitates and carbides [9-11].

In an experimental analysis of plastic deformation on the surface of specimens, it is advantageous to use contactless displacement sensing methods, allowing obtaining deformation fields in pre-selected areas. The digital image correlation (DIC) is one of the most advanced optical methods of displacement sensing and subsequent determination of strains on the surface of examined objects. The strain fields are calculated from the displacement fields by the Vic $2 \mathrm{D}$ program $[12,13]$.

The aim of this study was to compare the deformation behavior of both materials mentioned above using strain analysis completed by metallographic and fractographic studies and on the best of results to determine if the DIC method is suitable for different types of alloys.

\section{Experiment methodology}

\subsection{Experimental procedures}

The tensile tests were carried out on cylindrical specimens with the gauge length of $28 \mathrm{~mm}$ and the dia-

*Corresponding author: e-mail address: stamborska.michaela@gmail.com 
Ta ble 1. Chemical composition according to standards: 34CrMo4 steel ČN EN 10083-1/DIN 17200/ (wt.\%)

\begin{tabular}{ccccccc}
\hline $\mathrm{C}$ & $\mathrm{Mn}$ & $\mathrm{Si}$ & $\mathrm{P}$ & $\mathrm{S}$ & $\mathrm{Cr}$ & $\mathrm{Mo}$ \\
\hline $0.30-0.37$ & $0.60-0.90$ & $\max 0.40$ & $\max 0.035$ & $\max 0.035$ & $0.90-1.20$ & $0.15-0.30$ \\
\hline
\end{tabular}

Table 2. Chemical composition according to standards: IN 738LC superalloy (wt.\%)

\begin{tabular}{ccccccccc}
\hline $\mathrm{Ni}$ & $\mathrm{Cr}$ & $\mathrm{Co}$ & $\mathrm{Al}$ & $\mathrm{Ti}$ & $\mathrm{W}$ & $\mathrm{Mo}$ & $\mathrm{Ta}$ & $\mathrm{Nb}$ \\
\hline balance & $15.7-16.3$ & $8.2-9.0$ & $3.2-3.7$ & $3.2-3.7$ & $2.4-2.8$ & $1.5-2.0$ & $1.5-2.0$ & $0.6-1.1$ \\
\hline $\mathrm{Zr}$ & $\mathrm{B}$ & $\mathrm{Fe}$ & $\mathrm{Si}$ & $\mathrm{Mn}$ & $\mathrm{Cu}$ & $\mathrm{P}$ & $\mathrm{C}$ & $\mathrm{S}$ \\
\hline $0.03-0.08$ & $0.007-0.012$ & $\max 0.5$ & $\max 0.3$ & $\max 0.2$ & $\max 0.1$ & $\max 0.015$ & $0.09-0.13$ & $\max 0.015$ \\
\hline
\end{tabular}

Ta ble 3. The values of mechanical properties for 34CrMo4 steel measured by standard uniaxial tensile test

\begin{tabular}{cccc}
\hline Specimens & $\begin{array}{c}\text { Yield strength } \\
(\mathrm{MPa})\end{array}$ & $\begin{array}{c}\text { Ultimate tensile stress } \\
(\mathrm{MPa})\end{array}$ & $\begin{array}{c}\text { Strain field } \varepsilon_{x} \\
(-)\end{array}$ \\
\hline 1 & 937 & 1040 & 0.446 \\
2 & 958 & 1041 & 0.436 \\
3 & 941 & 1041 & 0.390 \\
\hline Average value & $945 \pm 28$ & $1041 \pm 1$ & $0.441 \pm 0.02$ \\
\hline
\end{tabular}

meter of $5 \mathrm{~mm}$. Stress-strain diagrams were obtained for three specimens of $34 \mathrm{CrMo} 4$ steel and three specimens of IN 738LC superalloy. The tensile test was realized with a deformation rate of $2.5 \times 10^{-3} \mathrm{~s}^{-1}$ on the experimental setup consisting of Zwick/Roel Z150 tensile machine with hydraulic grips and of the Canon 5D Mark II camera.

The evaluation of the strain fields was carried out by using an image correlation software Vic 2D. The principle of the method is based on scanning the stochastic black and white spotted pattern created on the surface of the examined object, for example, by spraying black paint on a white background. The observed area is divided by a virtual grid into smaller subareas called facets so that each of them would contain a characteristic part, with sufficient contrast, of the pattern. Based on the correlation of corresponding facets before and after deformation, the displacements of the individual points and strain fields are determined. In case of plane image correlations, the object deformations are determined by observation through one camera directed perpendicularly to the surface of the object. This procedure allows determining the deformation of the object in a level parallel to the image level of the camera [14-16].

The metallographic study was realized on crosssections of both materials. Samples of the steel as well as of the superalloy were grinded on abrasive paper $\mathrm{SiC}$ and polished with a diamond paste of grain size $1 \mu \mathrm{m}$ using a semi-automatic grinder. Etching reagents with compositions of $4 \mathrm{ml} \mathrm{HNO}_{3}+96 \mathrm{ml} \mathrm{C}_{2} \mathrm{H}_{5} \mathrm{OH}$ and $45 \mathrm{ml} \mathrm{C}_{2} \mathrm{H}_{5} \mathrm{OH}+5 \mathrm{ml} \mathrm{HCl}+2.5 \mathrm{~g} \mathrm{CuCl}_{2}$ were applied at a room temperature for $34 \mathrm{CrMo} 4$ steel and IN 738LC superalloy, respectively. The microstructure observation of the alloys in an etched condition, as well as the microanalysis, were performed using scanning electron microscope (SEM) JEOL JSM-6490 LV equipped with EDS analyzer INCA x-act. The fractographic study after the tensile tests was carried out using JEOL JSM-6490 LV microscope.

Microhardness was evaluated for both materials. Microindentation hardness testing was done using an FM-100 tester with Vickers indenter, and FM-ARS-900 semiautomated system. Five indentations under a constant load of $1.961 \mathrm{~N}$ were performed for $7 \mathrm{~s}$ in the center of the longitudinal section of each specimen taken from the tested bars and average values of HV0.2.

\subsection{Experimental materials}

The mechanical properties and deformation behavior of two different high-strength materials were compared, one being destined for pressure vessels, the second one for high-temperature applications.

\subsubsection{CrMo4 steel}

The first experiment was carried out on tensile specimens prepared from the $34 \mathrm{CrMo} 4$ steel of the chem- 

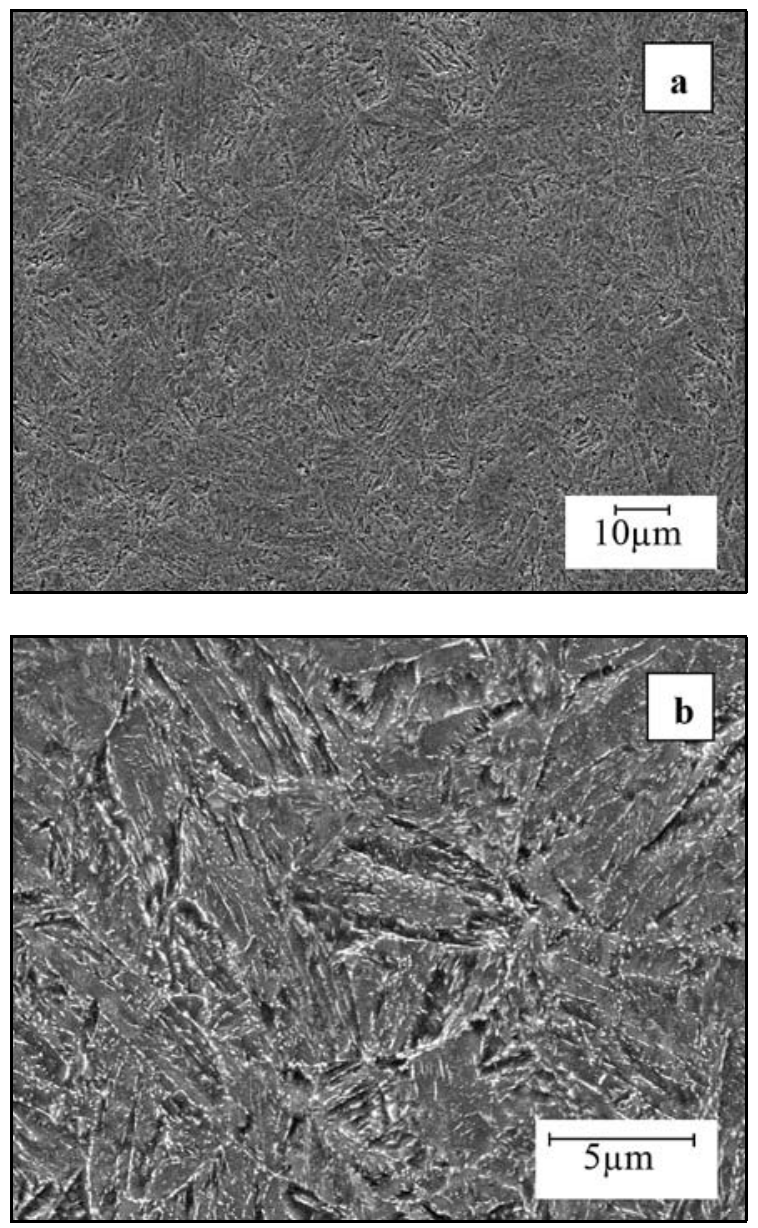

Fig. 1. SEM SEI micrographs of 34CrMo4 steel: (a) general view of fine-grained microstructure, b) detail of transformed martensite and carbides.

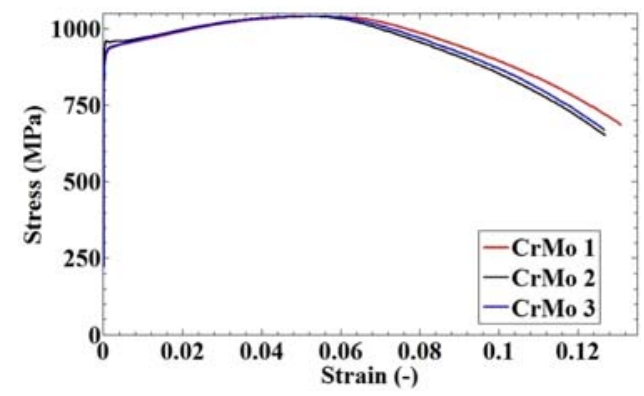

Fig. 2. The stress-strain diagram for three specimens of the $34 \mathrm{CrMo} 4$ steel.

ical composition shown in Table 1. Heat treatment of the steel consisted of austenitization at $850^{\circ} \mathrm{C}$ and water cooling followed by tempering at $640^{\circ} \mathrm{C}$ and water cooling.

\subsubsection{IN $738 L C$ superalloy}

The second experiment was performed on tensile
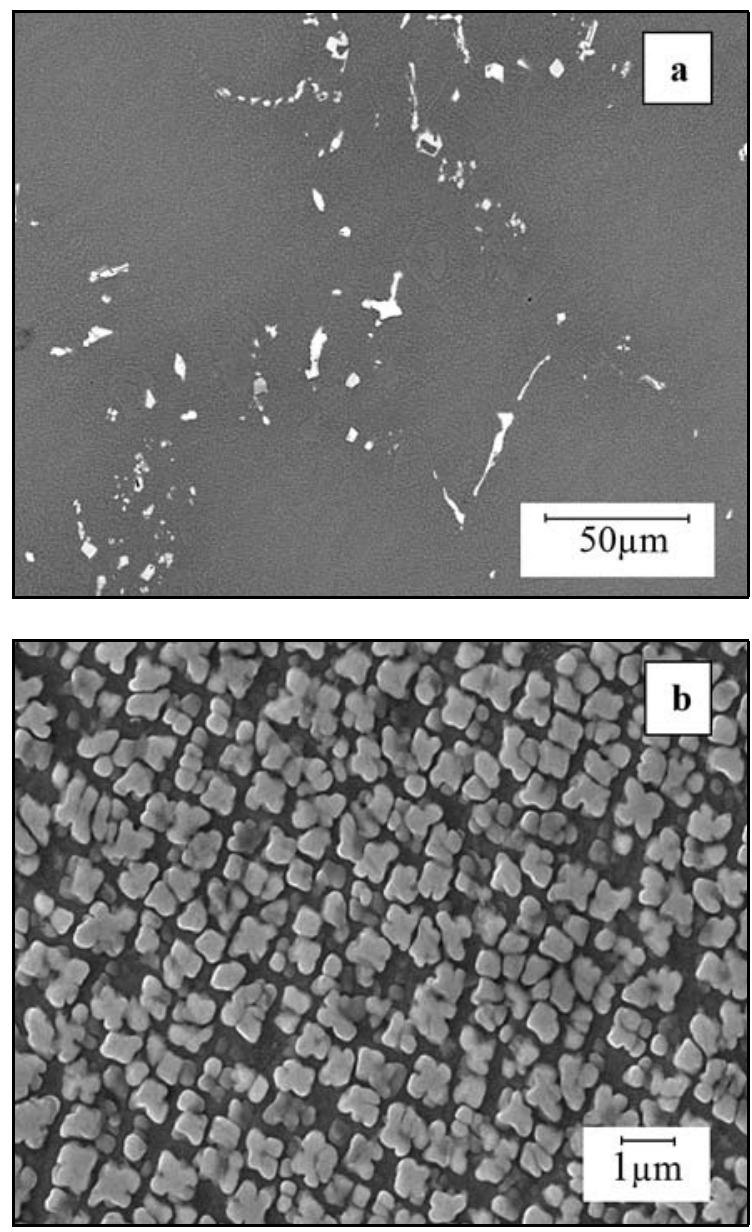

Fig. 3. SEM micrographs of IN 738LC superalloy: (a) BEC image of solid solution strengthened by $\gamma^{\prime}$-phase and carbides, (b) SEI detail of $\gamma^{\prime}$ precipitates in $\gamma$ solid solution.

specimens prepared from the nickel-base superalloy IN 738LC and supplied in a precipitation strengthened state by the society PBS Velká Bíteš, a.s. The chemical composition of tested alloy is given in Table 2. Before the tensile test cylindrical samples were submitted to hot isostatic pressing (HIP) at $1190{ }^{\circ} \mathrm{C}$ and $175 \mathrm{MPa}$ for 4 hours to reduce the amount of casting defects in the microstructure and eliminate premature cracking [17].

\section{Results and discussion}

\subsection{Microstructure and mechanical properties of 34CrMo4 steel}

The metallographic observation confirmed that the microstructure in quenched and tempered state was formed of transformed martensite and carbide precipitates (Fig. 1). The prior austenite grain size was estimated by the standard ČSN EN ISO 643 and 


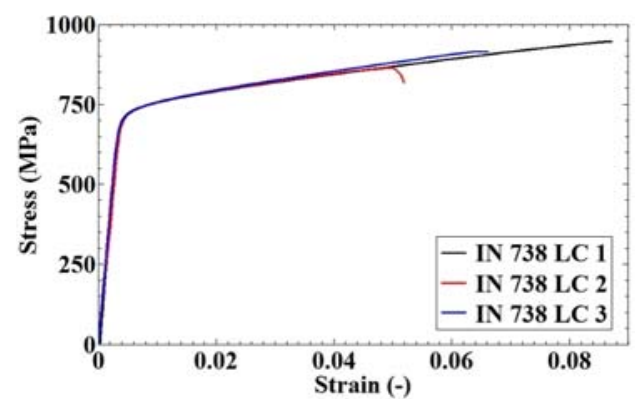

Fig. 4. The stress-strain diagram for three specimens of IN 738LC superalloy.

reached $G=14$. The average values of microhardness of martensite microstructure were of $320 \mathrm{HV} 0.2$.

Mechanical characteristics for the $34 \mathrm{CrMo} 4$ steel that were obtained by a tensile test are listed in Table 3 and are in good compliance with [18]. The deformation behavior of material with higher plasticity and high strength characteristics is confirmed in the stress-strain diagram plotted in Fig. 2.

\subsection{Microstructure and mechanical properties of IN 738LC superalloy}

The microstructure of superalloy consisted of $\gamma$ solid solution, $\gamma^{\prime}$ precipitates and carbides distributed in the $\gamma$ matrix (Fig. 3a). The typical morphology of $\gamma^{\prime}$ precipitates is detailed in Fig. 3b. The average values of microhardness measured on $\left(\gamma+\gamma^{\prime}\right)$ areas reached 381 HV0.2.

The measured values of mechanical properties obtained by a tensile test for IN 738LC superalloy are listed in Table 4 . The yield strength, as well as ultimate tensile stress, correspond to the given material [19]. The stress-strain diagram obtained from the tensile test of IN 738LC superalloy is shown in Fig. 4.

\subsection{The results obtained by DIC for 34CrMo4 steel}

The distribution of strain fields $\varepsilon_{x}(-)$ obtained by VIC 2D software for the $34 \mathrm{CrMo} 4$ steel is shown in Fig. 5 and corresponds to the last stage of the tensile test, when the rod forms a local contraction of the width (necking) and deforms further only in this one place until it breaks.

In places away from the neck, the tested rod does not extend. From the results for all three specimens displayed in Fig. 5, it could be seen that the values of strains shown in red in the narrowed areas, reach maximum values from 39 to $45 \%$.

\subsection{The strain rate of $34 \mathrm{CrMo4}$ steel}

The strain rate $\dot{\varepsilon}(t)$ was calculated according to
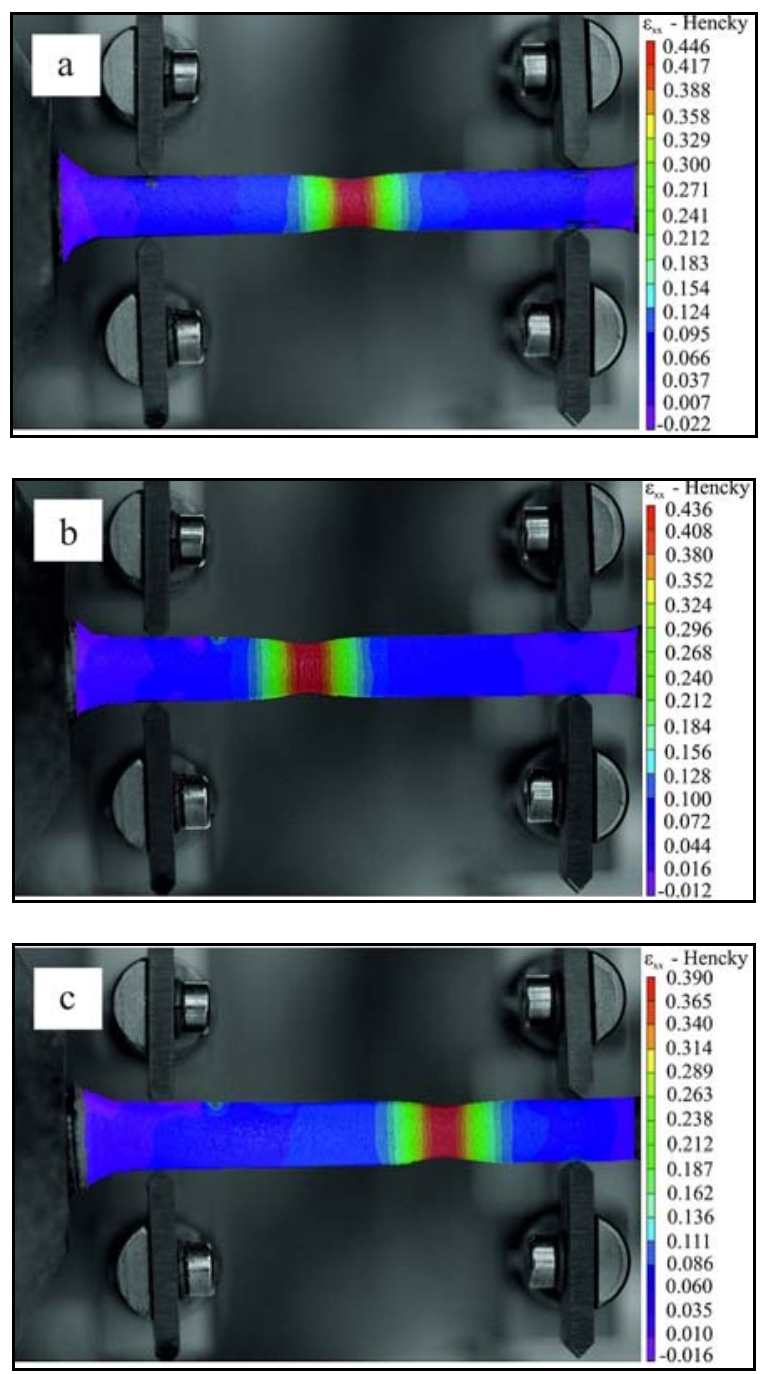

Fig. 5. The strain fields $\varepsilon_{x}(-)$ obtained by Vic 2D for $34 \mathrm{CrMo} 4$ steel for specimens: (a) 1, (b) 2 and (c) 3 .

Eq. (1) from measured values obtained by DIC:

$$
\dot{\varepsilon}(t)=\frac{\mathrm{d} \varepsilon}{\mathrm{d} t}=\frac{\mathrm{d}}{\mathrm{d} t}\left(\frac{L(t)-L_{0}}{L_{0}}\right)=\frac{1}{L_{0}} \frac{\mathrm{d} L}{\mathrm{~d} t}(t)=\frac{v(t)}{L_{0}},
$$

where $L_{0}$ is the original length, $L(t)$ is the length at time $t$ and $v(t)$ is the speed at which the ends are moving away from each other.

The strain rate diagrams of $34 \mathrm{CrMo} 4$ steel are shown in Fig. 6.

\subsection{The results obtained by DIC for IN $738 \mathrm{~L}$ C superalloy}

The results of strain field measurement $\varepsilon_{x}(-)$ obtained by VIC $2 \mathrm{D}$ software for IN 738LC superalloy are shown in Fig. 7. It can be seen that the values of strains shown in red in the narrowed area of the specimens, reach maximum values from 14 to $18 \%$ and 
Table 4. The values of the measured mechanical properties for IN 738LC superalloy obtained by standard uniaxial tensile test

\begin{tabular}{cccc}
\hline Specimens & $\begin{array}{c}\text { Yield strength } \\
(\mathrm{MPa})\end{array}$ & $\begin{array}{c}\text { Ultimate tensile stress } \\
(\mathrm{MPa})\end{array}$ & $\begin{array}{c}\text { Strain field } \varepsilon_{x} \\
(-)\end{array}$ \\
\hline 1 & 725 & 945 & 0.184 \\
2 & 721 & 864 & 0.139 \\
3 & 722 & 914 & 0.177 \\
\hline
\end{tabular}

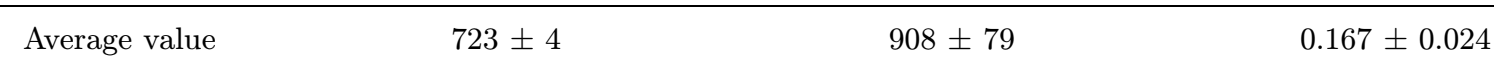
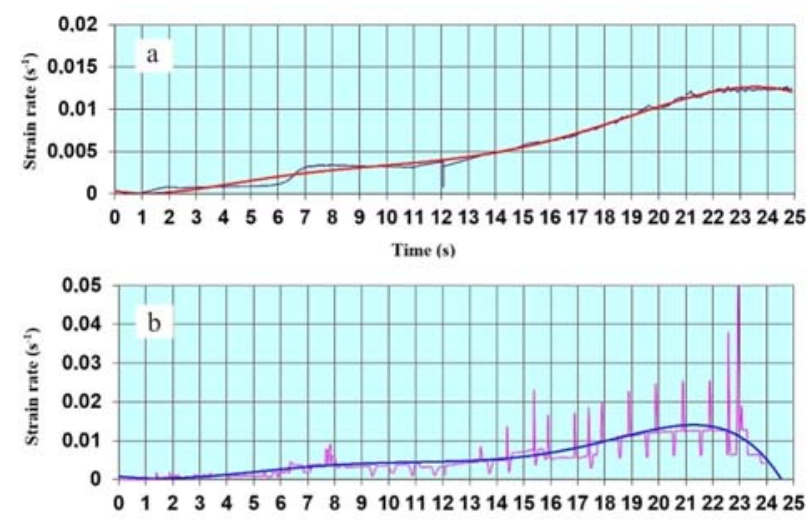

Time (s)

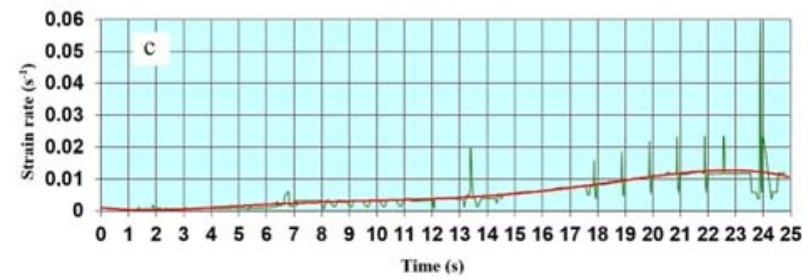

Fig. 6. The strain rate for $34 \mathrm{CrMo} 4$ for specimens: (a) 1 , (b) 2 and (c) 3 .

correspond to the last stage of tensile test, when the rod breaks without a local contraction of the width. Unlike the $34 \mathrm{CrMo} 4$ steel, the distributions of maximum values of strains are not uniform that is the cause of no necking. Cracking occurs in any area with the highest value of strain as seen in Fig. 7.

\subsection{The strain rate of IN $738 \mathrm{LC}$ superalloy}

The strain rate for IN 738 LC superalloy was calculated by the same Eq. (1) from measured values obtained by DIC, and the diagrams for all specimens are shown in Fig. 8.

\subsection{Fractography of $34 \mathrm{CrMo4}$ steel}

After the tensile test, the specimens of the $34 \mathrm{CrMo} 4$ steel showed ordinary cup-and-cone fractures with rosette star-type surfaces (Fig. 9). The magnified view of Fig. 9b of the fracture surface in
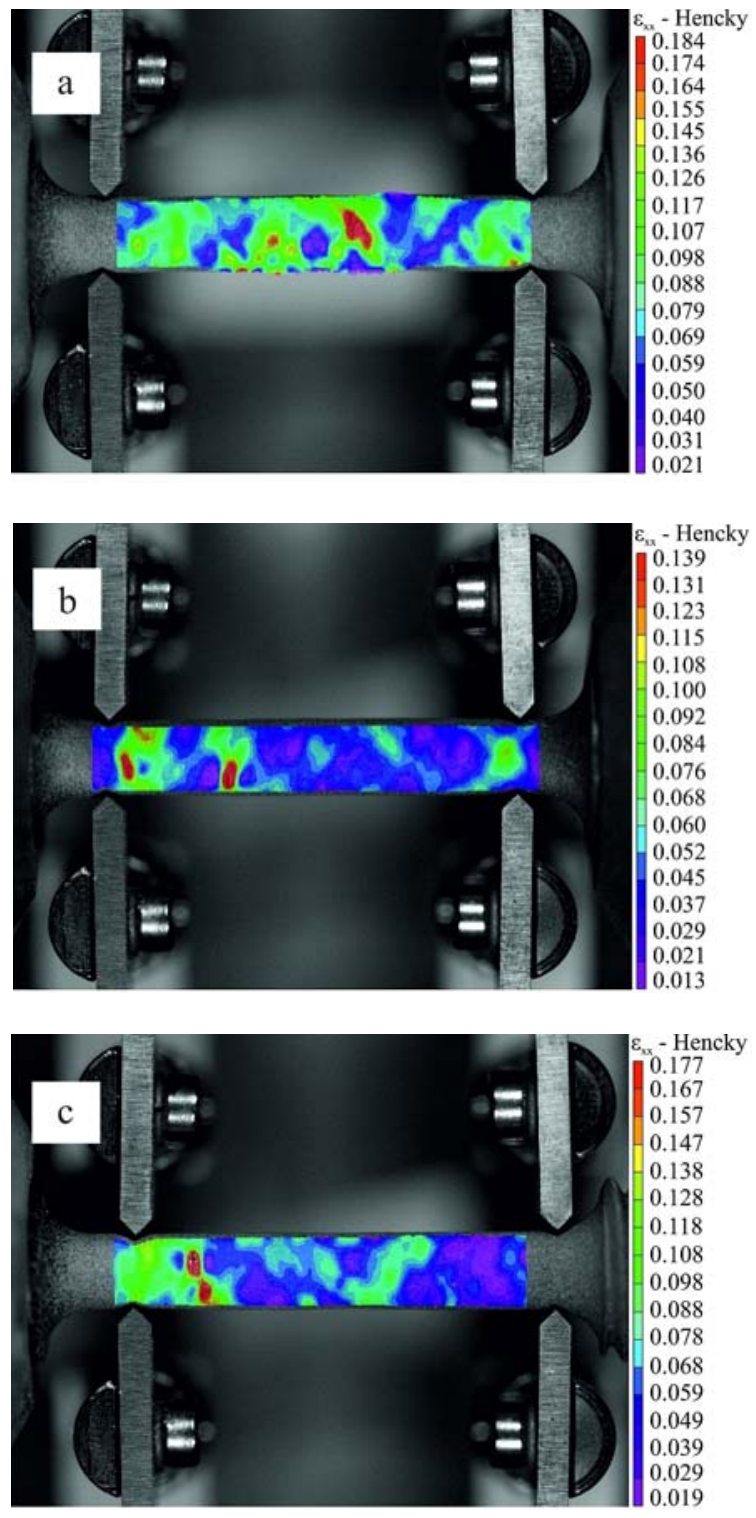

Fig. 7. The strain fields $\varepsilon_{x}(-)$ obtained by Vic $2 \mathrm{D}$ for IN 738LC for specimens: (a) 1, (b) 2 and (c) 3 .

Fig. 9a) displays transgranular fracture with dimples and deep secondary cracks that are typical for the ductile material. 

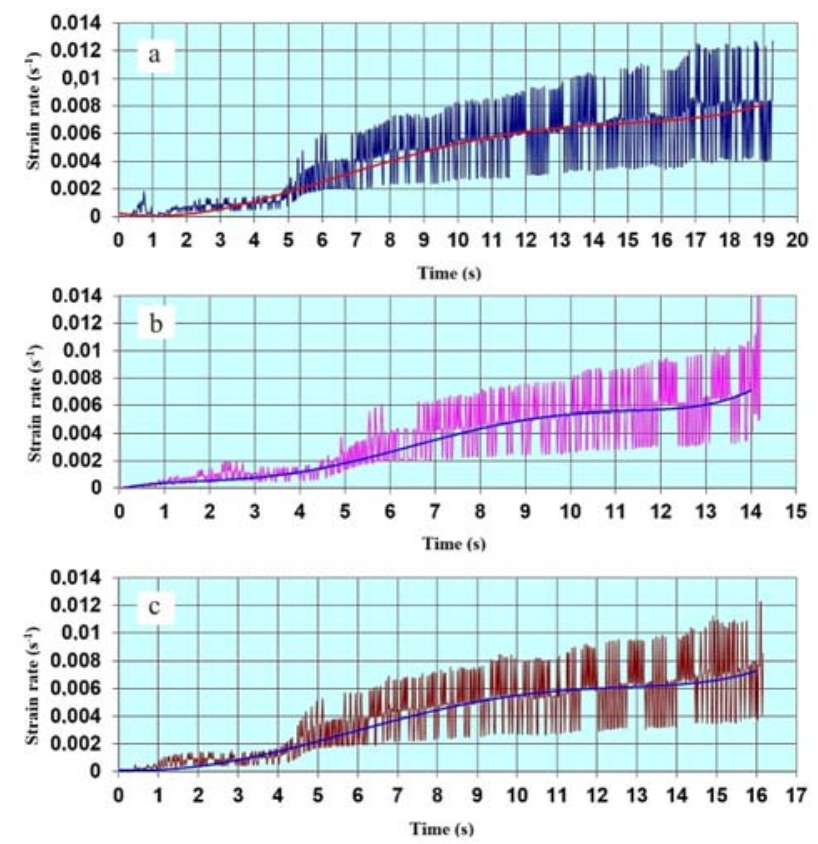

Fig. 8. The strain rate for IN 738 LC for specimens: (a) 1 , (b) 2 and (c) 3 .

\subsection{Fractography of IN 738 LC superalloy}

By general view, fracture surfaces of IN $738 \mathrm{LC}$ superalloy show intergranular or interdendritic fractures (Fig. 10a) surface with casting defect in the bottom. At higher magnifications, a more ductile feature with dimples or quasi-cleavage areas is typical for cracking of $\gamma$ matrix strengthened by $\gamma^{\prime}$ precipitates. The cracked MC carbides and decohesion at carbide/matrix interface are shown in Fig. 10b. Block type MC carbides as crack initiators at their interface with the matrix and failure propagated along this interface have cleavage feature [20].

\section{Conclusions}

Based on the results of comparative strain analysis of $34 \mathrm{CrMo} 4$ steel and IN 738LC following conclusions could be drawn:

The DIC method allows very well determining the magnitude of the strain fields and localization of the deformation area and is suitable for applying to both alloys with good plasticity and with higher brittleness. The method allowed us to determine the distribution and amount of deformation, at which the samples are fractured, but also to detect locations of defects or microstructure heterogeneities formed during the production of materials.

Both alloys are high strength materials. While the steel of sufficient homogeneity is characteristic by a sample construction and necking, the deformation be-
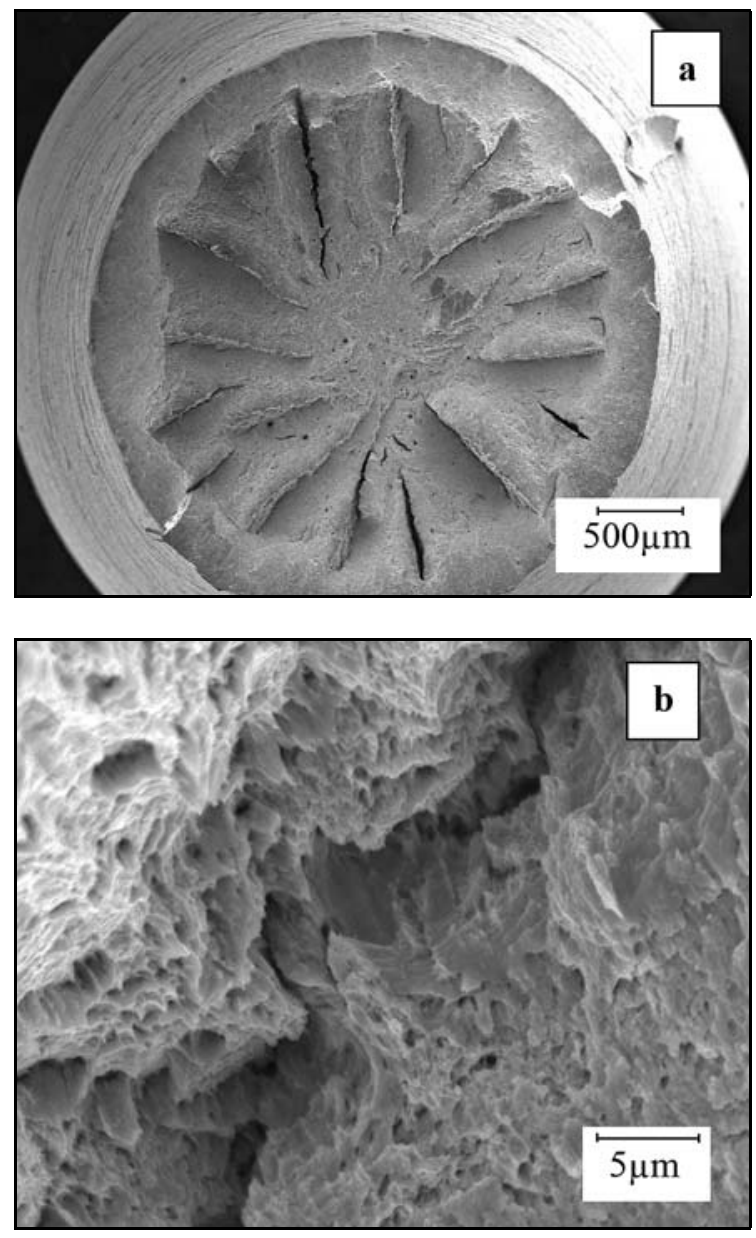

Fig. 9. SEM fractographs of the $34 \mathrm{CrMo} 4$ steel: (a) rosette star-type fracture and b) detail of ductile surface with secondary crack.

havior of IN 738LC superalloy shows higher brittleness due to the presence of $\mathrm{Ni} 3 \mathrm{Al}$ precipitates and carbides.

Maximum values of strains measured for $34 \mathrm{CrMo} 4$ steel by Vic $2 \mathrm{D}$ ranged from 39 to $45 \%$ and were located at the point of constriction as is marked in red in Fig. 3. The average values of tensile characteristics of 34CrMo4 steel reached $945 \mathrm{MPa}$ and $1041 \mathrm{MPa}$ for the yield strength and ultimate tensile stress, respectively. Higher plasticity of the samples during tensile testing was confirmed by necking, as well as by the tenacious character of fracture with ductile dimples.

The maximum values of strain fields $\varepsilon_{x}$ measured for IN738LC and calculated by Vic 2D ranged from 14 to $18 \%$. In the case of IN 738LC, the average tensile characteristics reached 723 and $908 \mathrm{MPa}$ for the yield strength and ultimate tensile stress, respectively. Lower plasticity of superalloy was confirmed not only by a large number of high strain areas occurred along the gauge part of samples but also by mixed nature of the fracture with a transcrystalline or interdendritic cracking with ductile dimples as well as quasi-cleavage facets. 

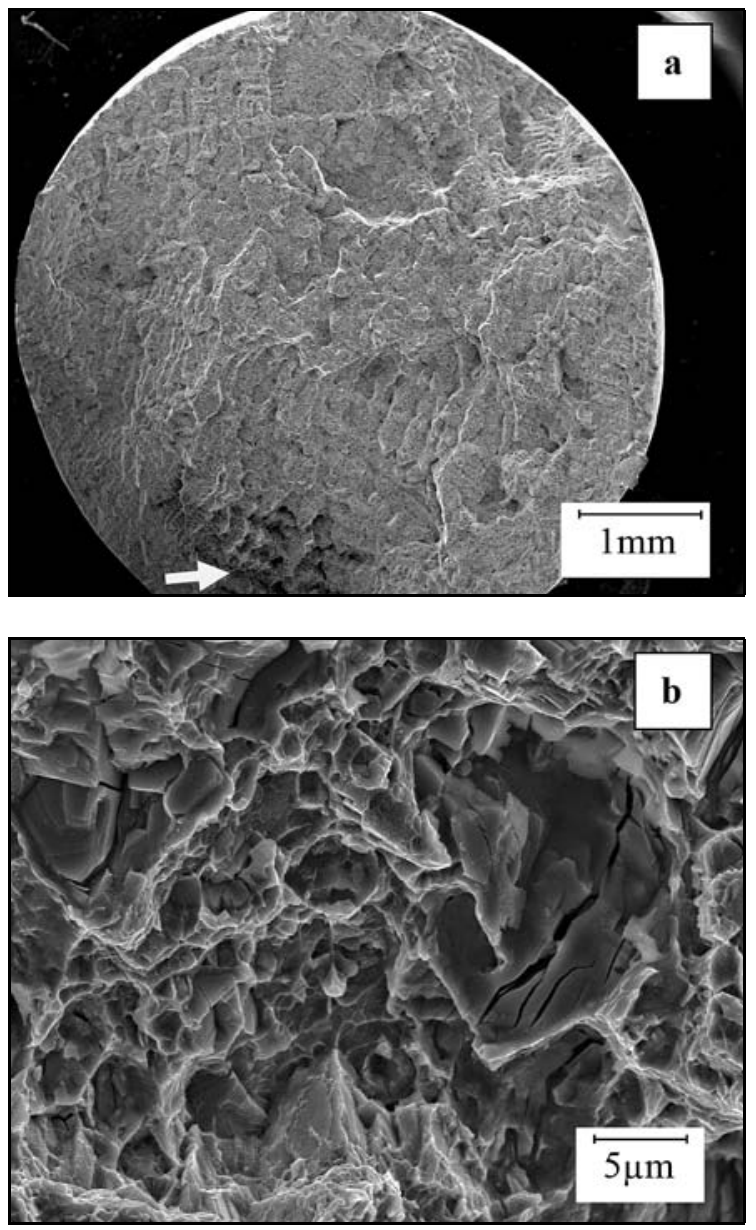

Fig. 10. SEM fractographs of IN 738LC specimens: (a) mixed feature of the fracture surface with casting defect in the bottom and (b) detail of ductile dimples and quasicleavage surfaces with fractured block shaped carbide.

Comparing the properties of both materials mentioned above it was found that the method of strain analysis, if completed by metallographic and fractographic studies, EDS microanalysis, and microhardness measurements, is suitable for establishment and understanding the deformation behavior of different types of materials.

\section{Acknowledgements}

This article has been elaborated in the framework of the project Opportunity for young researchers, reg. no. CZ.1.07/2.3.00/30.0016, supported by Operational Programme Education for Competitiveness and co-financed by the European Social Fund and the state budget of the Czech Republic and the Project No. LO1203 "Regional Materials Science and Technology Centre - Feasibility Program" funded by the Ministry of Education, Youth and Sports of the Czech Republic.

\section{References}

[1] Masahashi, N., Watanabe, S., Nomura, N., Semboshi, S., Hanada, S.: Intermetallics, 13, 2005, p. 717. doi:10.1016/j.intermet.2004.12.017

[2] Hendrych, A., Kvíčala, M., Matolin, V., Životský, O., Jandačka, P.: International Journal of Fracture, 168, 2011, p. 259. doi:10.1007/s10704-010-9573-7

[3] Kvíčala, M., Frydrýšek, K., Hendrych, A.: International Journal of Fracture, 181, 2013, p. 139. doi:10.1007/s10704-013-9819-2

[4] Fuentes, A. R. F., de Alcântara, N. G., Rodríguez, S. H., Ibarra, A. L.: Materials Research, 9, 2006, p. 153. doi:10.1590/S1516-14392006000200008

[5] Li, Y., Pan, X., Wang, G.: Key Engineering Materials, 579-580, 2013, p. 52. doi:10.4028/www.scientific.net/KEM.579-580.52

[6] Yan, Y. T., Sun, Z. L., Hu, G. Y., Hu, T. Q.: Key Engineering Materials, 500, 2012, p. 254. doi:10.4028/www.scientific.net/KEM.500.254

[7] Michel, J., Buršák, M., Mamuzić, I.: Metallurgija, 51, 2012 , p. 79.

[8] Salemi, A., Abdollah-Zadeh, A., Mirzaei, M., Assadi, H.: Materials Science and Engineering A, 492, 2008, p. 45 . doi:10.1016/j.msea.2008.02.043

[9] Rickenbacher, L., Etter, T., Hövel, S., Wegener, K.: Rapid Prototyping Journal, 19, 2013, p. 282. doi:10.1108/13552541311323281

[10] Balikci, E., Mirshams, R. A., Raman, A.: Journal of Materials Engineering and Performance, 9, 2000, p. 324. doi:10.1361/105994900770345999

[11] Razavi, S. H., Mirdamadi, Sh., Szpunar, J., Arabi, H.: Journal of Materials Science, 37, 2002, p. 1461. doi:10.1023/A:1014561705233

[12] Stamborská, M., Mareš, V., Kvíčala, M., Horsák, L.: Kovove Mater., 52, 2014, p. 377. doi:10.4149/km_2014_6_377

[13] Rossi, M., Pierron, F., Stamborská, M., Šimčák, F.: Experimental and Applied Mechanics, 4, 2013, p. 229. doi:10.1007/978-1-4614-4226-4_27

[14] Simčák, F., Stamborská, M., Huňady, R.: Chemické listy, 105, 2011, p. 564.

[15] Hagara, M., Schrötter, M.: American Journal of Mechanical Engineering, 1, 2013, p. 185. doi:10.12691/ajme-1-7-6

[16] Schrötter, M., Hagara, M., Kalina, M.: Applied Mechanics and Materials, 611, 2014, p. 490. doi:10.4028/www.scientific.net/AMM.611.490

[17] Losertová, M., Konečná, K., Juřica, J., Jonšta, P.: In: Proceedings of the 20th Anniversary International Conference on Metallurgy and Materials: METAL 2011. Ostrava, Tanger, s.r.o. 2011, p. 1039. ISBN 97880-87294-24-6.

[18] Material specification sheet Saarstahl-34CrMo4. http://www.saarstahl.com/

[19] Technical Data_Alloy IN-738. http://www. nickelinstitute.org/en/TechnicalLiterature/

[20] Mazur, Z., Luna-Ramírez, A., Juráez-Islas, J. A., Campos-Amezuca, A.: Engineering Failure Analysis, 12, 2005, p. 474. doi:10.1016/j.engfailanal.2004.10.002 